Lu Li, Xiaoyue Mu, Wenbo Liu, Zetian Mi, and Chao-Jun Li

\title{
A Simple and Efficient System for Combined Solar- Energy Harvesting and Reversible Hydrogen Storage
}

Published in:

Journal of the American Chemical Society, 2015, 137 (24), pp 75767579

Copyright 2015 American Chemical Society.

doi: $10.1021 / j a c s .5 b 03505$

http://pubs.acs.org/doi/abs/10.1021/jacs.5b03505 


\title{
A Simple and Efficient System for Combined Solar- Energy Harvesting and Reversible Hydrogen Storage
}

\author{
$\mathrm{Lu} \mathrm{Li},{ }^{\dagger, \ddagger}$ Xiaoyue $\mathrm{Mu},{ }^{\dagger}$ Wenbo Liu, ${ }^{\dagger}$ Zetian $\mathrm{Mi}^{*},{ }^{*}$ and Chao-Jun $\mathrm{Li}^{*}{ }^{*}{ }^{\dagger}$ \\ ${ }^{\dagger}$ Department of Chemistry and FQRNT Centre for Green Chemistry and Catalysis, McGill \\ University, 801 Sherbrooke Street West, Montreal, QC H3A oB8, Canada \\ ${ }^{\star}$ Department of Electrical and Computer Engineering, McGill University, 3480 Universi- \\ ty Street, Montreal, QC H3A oE9, Canada
}

\begin{abstract}
Solar energy harvesting and hydrogen economy are the two most important green energy endeavors for the future. However, a critical hurdle to the latter is how to safely and densely store and transfer hydrogen. Herein, we developed a reversible hydrogen storage system based on low-cost liquid organic cyclic hydrocarbons at room temperature and atmospheric pressure. A facile switch of hydrogen addition (> 97\% conversion) and release (>99\% conversion) with superior capacity of $7.1 \mathrm{H}_{2}$ wt\% can be quickly achieved over a rationally optimized platinum catalyst with high electron density, simply regulated by dark/light conditions. Furthermore, the photo-driven dehydrogenation of cyclic alkanes gave an excellent apparent quantum efficiency of $6.0 \%$ under visible light illumination (420-600 nm) without any other energy input, which provides an alternative route to artificial photosynthesis for directly harvesting and storing solar energy in the form of chemical fuel.
\end{abstract}

Since the first discovery of water photolysis on $\mathrm{TiO}_{2}$ electrodes by Honda and Fujishima in the early 1970s, utilizing solar energy to either produce renewable fuels ${ }^{1-3}$ or trigger valuable transformations ${ }^{4-7}$ has become one of the most sustainable and promising strategies to solve the growing global concerns on energy supply and environmental issues, ${ }^{8}$ which are among the biggest challenges facing our society today. Thus far, a variety of artificial photosynthesis systems have been established to fix the energy of sunlight into chemical energy, which include the photocatalytic conversion of water ${ }^{9-11}$ and carbon dioxide ${ }^{12,13}$ into useful molecules (e.g., $\mathrm{H}_{2}, \mathrm{CO}$ and hydrocarbons) and their applications in the fuel-cells for power generation. ${ }^{14,15}$ Specifically, clean $\mathrm{H}_{2}$ produced from the watersplitting reaction is a very attractive energy storage carrier due to its exceptional mass

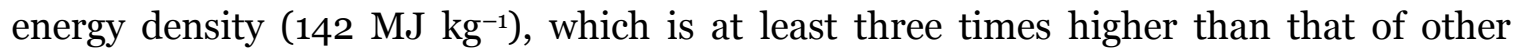


chemical fuels. ${ }^{16}$ Unfortunately, the problem of hydrogen storage and transportation is a major obstacle to employing hydrogen as a universal fuel since hydrogen has a very low volumetric density at ambient conditions. This has prompted great efforts to replace the current method of using compressed gas hydrogen (30-70 MPa) or liquid hydrogen (-253 ${ }^{\circ} \mathrm{C}$ ) in tanks. ${ }^{17}$ The major challenge is how to design a high capacity system with superior reversibility that can realize both hydrogen release and regeneration processes under practical conditions. ${ }^{18}$ Diverse models based on metal-organic frameworks, ${ }^{19}$ metal hydrides $^{20}$ and boron-nitrogen materials ${ }^{21}$ have been established and examined intensively.

To achieve economical and high-density hydrogen storage, it is preferable to construct the system based on abundant and lightweight elements. In this regard, a promising strategy is to add hydrogen to the unsaturated aromatic hydrocarbons that contain only carbon and hydrogen atoms. ${ }^{22}$ For instance, benzene, the simplest aromatics, can bear six hydrogen atoms to form cyclohexane through a metal catalyzed hydrogenation reaction. ${ }^{23}$ Obviously, as one of the most widely used industrial petrochemicals, the bulk market price of benzene (less than one dollar per kilogram) is highly competitive with other hydrogen storage materials. Furthermore, both benzene and produced cyclohexane (hydrogen carrier) are very stable and readily available for transportation using the current liquid fossil fuel distribution infrastructure. However, this potential hydrogen storage system suffers from a severe limitation that the dehydrogenation of cyclohexane is highly endothermic. Owing to the large positive Gibbs free energy (Figure S1), an elevated temperature $\left(>300{ }^{\circ} \mathrm{C}\right.$ ) is always required for hydrogen release, ${ }^{24}$ which is not suitable for practical applications and also inevitably results in the formation of coke.

Based on our recent work on the photoinduced methane conversion, ${ }^{25-27}$ we reasoned that photo-energy should be effective to overcome the intrinsic thermodynamic constraint of activating $\mathrm{C}-\mathrm{H}$ bonds of cyclic alkanes and access easy hydrogen release under ambient conditions. Herein, we designed a reversible hydrogen storage/release cycle based on the metal-catalyzed hydrogenation and photoinduced dehydrogenation of organic cyclic hydrocarbons reactions at room temperature. More importantly, the cleavage of six covalent $\mathrm{C}-\mathrm{H}$ bonds from one cyclohexane molecule to form hydrogen and benzene stores comparable amount of energy to that of splitting one water molecule (Equations 1 and 2), indicating a new approach to the solar energy harvesting.

$$
\begin{gathered}
2 \mathrm{H}_{2} \mathrm{O}(\mathrm{g}) \rightarrow 2 \mathrm{H}_{2}(\mathrm{~g})+\mathrm{O}_{2}(\mathrm{~g}), \Delta \mathrm{H}_{(298 \mathrm{~K})}=484 \mathrm{~kJ} / \mathrm{mol} \\
\mathrm{C}_{6} \mathrm{H}_{12}(\mathrm{~g}) \rightarrow \mathrm{C}_{6} \mathrm{H}_{6}(\mathrm{~g})+3 \mathrm{H}_{2}(\mathrm{~g}), \Delta \mathrm{H}_{(298 \mathrm{~K})}=206 \mathrm{~kJ} / \mathrm{mol} .
\end{gathered}
$$


Metal-semiconductor hybrids are ideal candidates for the fabrication of visible-light photocatalysts. In order to develop an efficient catalyst for the hydrogen release from cyclohexane under visible light, we synthesized a series of noble metal (Au, Pt, Pd, Ir and $\mathrm{Ru}$ ) modified $\mathrm{TiO}_{2}$ nanoparticles (NPs) by chemically reducing the corresponding metal precursors in a $\mathrm{NaBH}_{4}$ aqueous solution in the presence of commercialized Degussa P25 $\mathrm{TiO}_{2}$ (particle size, $\sim 25 \mathrm{~nm}$; Brunauer-Emmett-Teller (BET) surface area, $55.2 \mathrm{~m}^{2} \mathrm{~g}^{-1}$; anatase/rutile phase ratio, 4/1) at room temperature. The as-synthesized metal@ $\mathrm{TiO}_{2}$ hybrid materials were tested as photocatalysts for the non-oxidative dehydrogenation of cyclohexane under visible light ( $>420 \mathrm{~nm}$ ) from a $300-\mathrm{W}$ xenon lamp. To eliminate the photo-thermal effect, a cooling system was employed to keep the reaction temperature

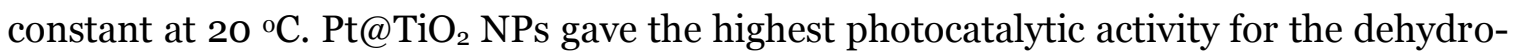
genation reaction among all the samples tested under identical conditions (Figure S2). We then set out to further optimize Pt@TiO ${ }_{2}$ NPs by altering the Pt content, $\mathrm{NaBH}_{4}$ concentration and $\mathrm{pH}$ value during the preparation procedure (Table S1). Finally, the optimized Pt@ $\mathrm{TiO}_{2}$ NPs with a platinum content of 5 wt\% were carefully prepared by using 20 equiv of $\mathrm{NaBH}_{4}$ (in terms of platinum) at pH 10, designated as $\mathrm{Pt} @ \mathrm{TiO}_{2}-\mathrm{N}$. Transmission electron microscopy (TEM, Figures 1a and 1b) images revealed that Pt species were highly dispersed on the surface of $\mathrm{TiO}_{2}$ with an exposed (111) facet. The Pt size distribution derived from TEM measurements fits well in a logarithmic normal distribution with a mean diameter of $3.2 \mathrm{~nm}$ (Figure 1c). The powder X-ray diffraction (XRD) measurements confirm the formation of metallic $\mathrm{Pt}^{\circ}$ species with a high degree of crystallinity since three characteristic peaks of $\mathrm{Pt}^{\circ}$ at $2 \theta=41^{\circ}, 46^{\circ}$ and $67^{\circ}$ can be clearly detected from the sample (Figure 1d). 

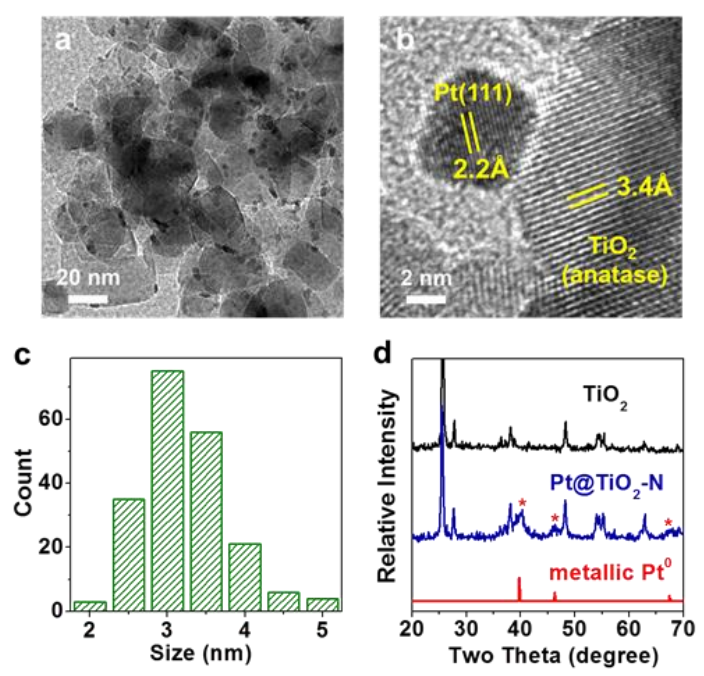

Figure 1. General characterization. (a) Low-, (b) high-resolution TEM images, (c) size distribution and (d) powder X-ray diffraction patterns of the as-synthesized Pt@TiO ${ }_{2}$ NPs with a platinum content of 5 wt\%.

The photocatalytic cyclohexane dehydrogenation reaction over the optimal $\mathrm{Pt} @ \mathrm{TiO}_{2}-\mathrm{N}$ led to the formation of benzene with nearly stoichiometric amounts of $\mathrm{H}_{2}$ (3 equiv). Using $10 \mathrm{mg}$ of $\mathrm{Pt} @ \mathrm{TiO}_{2}-\mathrm{N}$ and $100 \mu \mathrm{mol}$ of cyclohexane, a conversion of 99\% and a benzene selectivity of nearly $100 \%$ were achieved after 2-hour visible light irradiation (Figure 2a). The carbon mass balances during the conversion were close to $100 \%$ and only a trace amount of methane and carbon dioxide by-products were detected by gas chromatography. The control experiments have shown that the reaction does not proceed at all in the dark or in the absence of Pt species (exemplified by using pure $\mathrm{TiO}_{2}$ ), confirming that the dehydrogenation of cyclohexane to benzene by $\mathrm{Pt} @ \mathrm{TiO}_{2}-\mathrm{N}$ is a photocatalytic process and the Pt species behave as the active sites for reaction.

To gain a better understanding of the nature of the catalytic active sites, we have prepared another Pt modified $\mathrm{TiO}_{2}$ through the photo-reduction of $\mathrm{PtCl}_{6}{ }^{2-}$ precursor in a mixture of methanol/water solution (designated as $\mathrm{Pt} @ \mathrm{TiO}_{2}-\mathrm{M}$ ). Interestingly, although the content, shape and size of Pt species in $\mathrm{Pt} @ \mathrm{TiO}_{2}-\mathrm{M}$ are similar to those in $\mathrm{Pt} @ \mathrm{TiO}_{2}-\mathrm{N}$, as confirmed by TEM and XRD, the photoactivity of $\mathrm{Pt} @ \mathrm{TiO}_{2}-\mathrm{M}$, however, was very low for cyclohexane dehydrogenation under the same reaction conditions (Figure 2a). As shown in the X-ray photoelectron spectroscopy (XPS) spectra (Figure 2b), the Pt4f peaks of $\mathrm{Pt} @ \mathrm{TiO}_{2}-\mathrm{N}$ are negatively shifted (70.4 eV) compared to the standard binding energies of metallic $\mathrm{Pt}^{\circ}(71.1 \mathrm{eV}),{ }^{28}$ indicating that the Pt species in $\mathrm{Pt} @ \mathrm{TiO}_{2}-\mathrm{N}$ possess a frac- 
tion of negative charge; whereas the Pt4f peaks of $\mathrm{Pt} @ \mathrm{TiO}_{2}-\mathrm{M}$ remain almost unchanged (71.o eV). These results imply that the Pt species with high electron density, which can act as Lewis base sites, are highly beneficial to the dehydrogenation process.
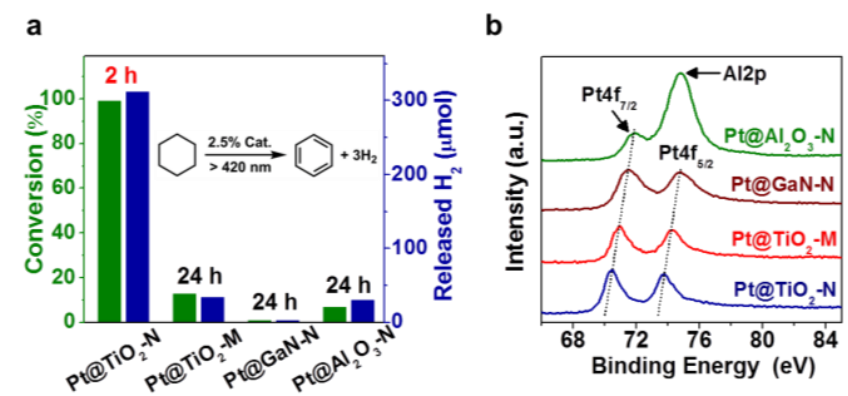

Figure 2. Visible-light-driven cyclohexane dehydrogenation reactions. (a) Cyclohexane conversion and hydrogen release over different Pt modified catalysts under visible light. (b) XPS spectra of Pt4ffor the different Pt modified catalysts. Reaction conditions were as follows: $100 \mu \mathrm{mol}$ of cyclohexane and $10 \mathrm{mg}$ of $\mathrm{Pt} @ \mathrm{TiO}_{2}-\mathrm{N}$ upon visible light (> $42 \mathrm{O} \mathrm{nm}$ ) irradiation for 2 hours (or 24 hours in the cases of other catalysts) at $20^{\circ} \mathrm{C}$.

Besides $\mathrm{TiO}_{2}, \mathrm{GaN}$ and $\mathrm{Al}_{2} \mathrm{O}_{3}$ were also used as supporting-substrates for the cyclohexane dehydrogenation reaction. As shown in Figure 2a, the performances of Pt@GaN-N and $\mathrm{Pt} @ \mathrm{Al}_{2} \mathrm{O}_{3}-\mathrm{N}$ were very poor under visible light irradiation, although the band gap and band position of $\mathrm{GaN}$ are similar to $\mathrm{TiO}_{2}$. The binding energy of Pt deposited on $\mathrm{GaN}$ or $\mathrm{Al}_{2} \mathrm{O}_{3}$ is also higher than that on $\mathrm{TiO}_{2}$, as evidenced by XPS (Figure 2b). Compared with other supports, a strong chemical interaction between platinum metal and $\mathrm{TiO}_{2}$ support exists due to the electron transfer from $\mathrm{TiO}_{2}$ to $\mathrm{Pt}$, which is called "Strong MetalSupport Interaction (SMSI)" and first reported by Tauster et al. ${ }^{29}$ The electron transfer from $\mathrm{TiO}_{2}$ to $\mathrm{Pt}$ is the reason for the formation of negatively charged Pt species. Specifically, under the reduction of $\mathrm{NaBH}_{4}, \mathrm{TiO}_{2}$ will generate oxygen vacancies and $\mathrm{Ti}^{3+}$ defects in the vicinity of Pt metal, which results in electron transfer from $\mathrm{Ti}^{3+}$ to Pt particles. ${ }^{30}$ These results indicate that $\mathrm{TiO}_{2}$-support draws a significant effect on the catalytic performance through altering the electronic property of the loaded Pt species. ${ }^{31}$

Nanosized Pt are visible-light-active species due to the intraband electron transitions, ${ }^{32,33}$ whereas $\mathrm{TiO}_{2}$ substrate can only absorb photons in the ultraviolet region. Therefore, the metallic Pt species in this study essentially act as both sensitizers to ab- 
sorb resonant photons, and active sites to facilitate the dehydrogenation reaction. As illustrated in Figure S3, upon visible light irradiation, the photoexcited hot electrons of Pt species can be temporarily added to an empty $\mathrm{C}-\mathrm{H} \sigma^{*}$-antibonding orbital of the adsorbed cyclohexane to active and homolytically cleave its $\mathrm{C}-\mathrm{H}$ bond, followed by the formation of an $\mathrm{H}$ atom which then couples with another $\mathrm{H}$ atom to produce $\mathrm{H}_{2}$. It is worth pointing out that the alkane dehydrogenation process does not consume extra electrons ${ }^{25}$ and thus, the photoexcited electrons will finally fall back to Pt. This mechanism is consistent with the experimental and XPS results that the Pt species with high electron density (low electron binding energy), which can offer electrons efficiently, are critical to access a high reactivity to the cyclohexane dehydrogenation reaction under visible light.

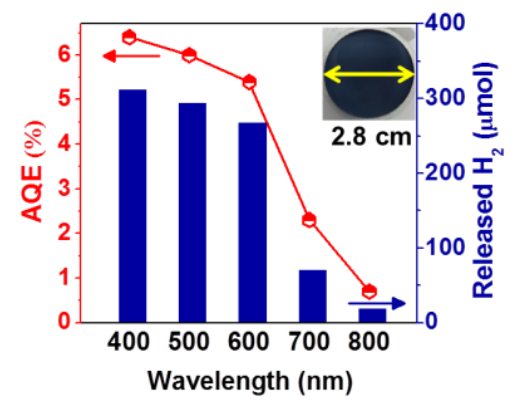

Figure 3. Apparent quantum efficiency ( $A Q E)$ (red line and hexagon symbol, left axis) and released $\mathrm{H}_{2}$ (blue columns, right axis) as a function of wavelength of the incident light. The inset shows a typical powdered Pt@TiO ${ }_{2}-\mathrm{N}$ sample spread evenly at the bottom of the closed quartz reactor.

To identify the effective spectral range and quantum efficiency, wavelength dependence experiments were carried out using a series of filters. As shown in Figure 3, the photocatalytic activity still remained a high level around $600 \mathrm{~nm}$, but decreased dramatically when the wavelength of light irradiation was longer than $700 \mathrm{~nm}$. The apparent quantum efficiency $\left(\mathrm{H}_{2}\right.$ produced per photon consumed) between $420-600 \mathrm{~nm}$ was calculated to be ca. $6.0 \%$, which rivals previously reported best performing solar water slitting devices without any external bias voltage.

During the cyclohexane dehydrogenation reaction, only cyclohexene intermediate was observed, whereas 1,3-cyclohexadiene was not detected. The control experiment indicated that 1,3-cyclohexadiene can either directly lose hydrogen to form benzene or react with cyclohexene to form benzene and cyclohexane over $\mathrm{Pt} @ \mathrm{TiO}_{2}-\mathrm{N}$ under visible light 
irradiation. Both reactions are extremely fast (within few seconds). Taken together, a plausible mechanism was proposed in Scheme 2. The reaction starts with the activation of cyclohexane $\mathrm{C}-\mathrm{H}$ bonds on the exposed Pt facets. Upon visible light irradiation, cyclohexane loses two hydrogen atoms to form cyclohexene. 1,3-cyclohexadiene produced from the further dehydrogenation of cyclohexene can quickly go through the dehydrogenation process or react with cyclohexene to form benzene.

\section{Scheme 2. Proposed photocatalytic dehydrogenation mechanism}

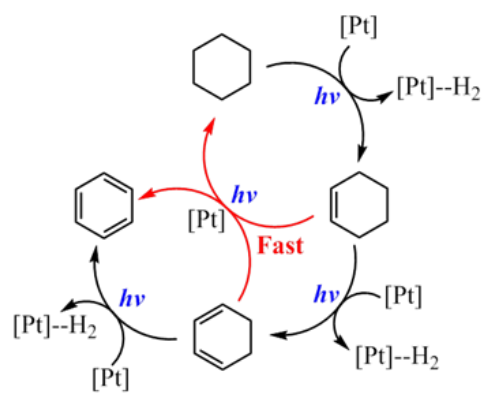

After the dehydrogenation reaction, the produced hydrogen can very slowly add back into benzene to form cyclohexane again under darkness at room temperature in the presence of $\mathrm{Pt} @ \mathrm{TiO}_{2}-\mathrm{N}$. In contrast, no hydrogenation product was obtained in the absence of Pt@ $\mathrm{TiO}_{2}-\mathrm{N}$. The hydrogenation process can be accelerated dramatically under slightly higher temperature. As shown in Figure 4a, a hydrogenation conversion of $97 \%$ can be achieved within one hour at $50^{\circ} \mathrm{C}$. Furthermore, toluene/methylcyclohexane and xylene/1,4-dimethylcyclohexane systems also work well for hydrogen storage (Figure 4a) and release (Figure 4b) under the same conditions, indicating a wide applicability of our strategy. 


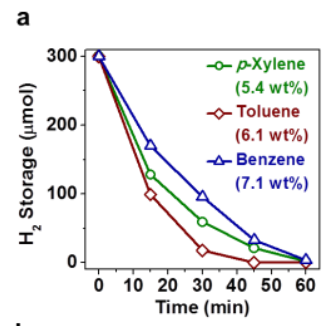

C
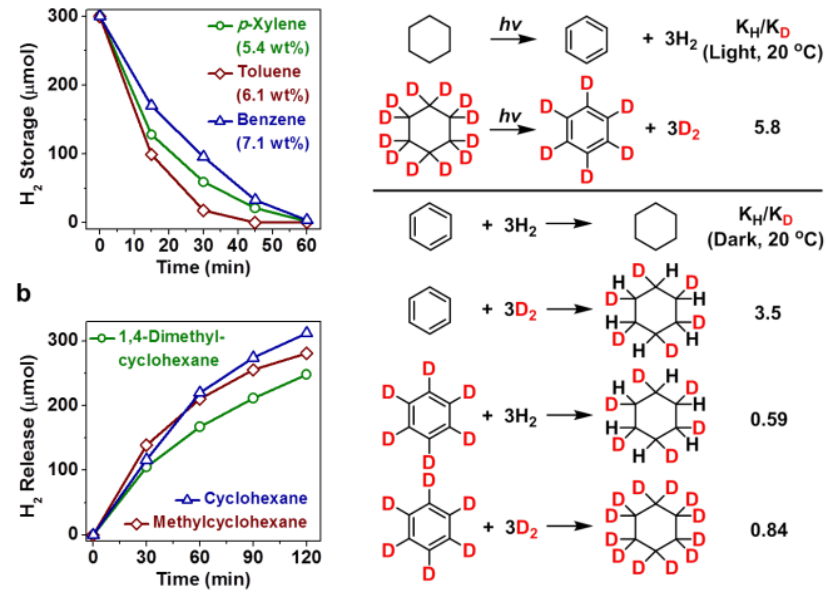

Figure 4. Kinetic studies on the hydrogen addition and release processes. (a) Time courses of hydrogen addition (30o $\mu \mathrm{mol}$ ) onto different aromatics (10o $\mu \mathrm{mol}$ ) over Pt@TiO $-\mathrm{N}$ under dark at $50^{\circ} \mathrm{C}$. (b) Plots of hydrogen release from different cyclic alkanes $(100 \mu \mathrm{mol})$ as a function of time over Pt@TiO ${ }_{2}-\mathrm{N}$ under visible light irradiation (> $42 \mathrm{O} \mathrm{nm}$ ) at $2 \mathrm{O}^{\circ} \mathrm{C}$. (c) Kinetic isotope effects in the dehydrogenation and hydrogenation processes.

To gain the mechanistic insights of different hydrogen transfer steps, the deuterium kinetic isotope effects (KIE) for both dehydrogenation and hydrogenation processes were determined comprehensively (Figure 4c). In the case of the dehydrogenation reaction, a high KIE $\left(k_{\mathrm{H}} / k_{\mathrm{D}}\right)$ of 5.8 was determined through parallel reactions by using the same amount of cyclohexane and cyclohexane- $d_{12}\left(\mathrm{C}_{6} \mathrm{D}_{12}\right)$, indicating that the $\mathrm{C}-\mathrm{H}$ bond cleavage is the rate-determining step. On the other hand, kinetic studies for the hydrogenation reaction were performed by using four different combinations including benzene $/ \mathrm{H}_{2}$, benzene $/ \mathrm{D}_{2}$, benzene- $d_{6} / \mathrm{H}_{2}$ and benzene- $d_{6} / \mathrm{D}_{2}$. The hydrogenation rate of benzene $/ \mathrm{D}_{2}$ was much lower than that of benzene $/ \mathrm{H}_{2}\left(k_{\mathrm{H}} / k_{\mathrm{D}}=3 \cdot 5\right)$, whereas a large inverse secondary isotope effect was observed in benzene- $d_{6} / \mathrm{H}_{2}\left(k_{\mathrm{H}} / k_{\mathrm{D}}=0.59\right)$ since the hybridization of carbon changes from $s p^{2}$ to $s p^{3}$ during the reaction. ${ }^{34}$ In benzene- $d_{6} / \mathrm{D}_{2}$ case, the overall KIE value is close to one since both primary isotope and inverse secondary isotope effects exist in the system which can neutralize each other to a certain extent.

In summary, our detailed studies have shown that the abundant and low-cost petrochemicals can be made possible for large scale reversible hydrogen storage/release. The 
apparent quantum efficiency for solar-to-hydrogen conversion can reach $6 \%$ under white light illumination, which can be further improved by optimizing the photon absorption. Compared with on-board hydrogen storage, this strategy is more promising for stationary applications due to the requirement of light. The efforts to further reduce the amount of Pt and develop other inexpensive metal catalysts are in progress. 


\section{ASSOCIATED CONTENT}

\section{Supporting Information}

Experimental procedures and analytical data. This material is available free of charge via the Internet at http://pubs.acs.org.

\section{AUTHOR INFORMATION}

\section{Corresponding Author}

zetian.mi@mcgill.ca

cj.li@mcgill.ca

\section{Notes}

The authors declare no competing financial interest.

\section{ACKNOWLEDGMENT}

This work was financially supported by the Canada Research Chair (Tier 1) foundation, the Natural Sciences and Engineering Research Council of Canada, the Fonds de recherchésur la nature et les technologies, Canada Foundation for Innovation (CFI), U.S. Army Research Office, and McGill University.

\section{REFERENCES}

(1) (a) Kudo, A.; Miseki, Y. Chem. Soc. Rev. 2009, 38, 253. (b) Nocera, D. G. Acc. Chem. Res. 2012, 45767.

(2) Habisreutinger, S. N.; Mende, L. S.; Stolarczyk, J. K. Angew. Chem. Int. Ed. 2013, 52, 7372.

(3) Kim, D.; Sakimoto, K. K.; Hong, D.; Yang, P. Angew. Chem. Int. Ed. 2015, 54, 3259.

(4) Nicewicz, D. A.; MacMillan, D. W. C. Science 2oo8, 322, 77.

(5) Yoon, T. P.; Ischay, M. A.; Du, J. Nat. Chem. 2010, 2, 527.

(6) Ghosh, I.; Ghosh, T.; Bardagi, J. I.; König, B. Science 2014, 346, 725.

(7) Huo, H.; Shen, X.; Wang, C.; Zhang, L.; Röse, P.; Chen, L.; Harms, K.; Marsch, M.; Hilt, G.; Meggers, E. Nature 2014, 515, 100.

(8) Concepcion, J. J.; House, R. L.; Papanikolas, J. M.; Meyer, T. J. Proc. Natl. Acad. Sci. USA 2012, 109, 15560. 
(9) Khan, S. U. M.; Shahry, M. A.; Ingler Jr., W. B. Science 2002, 297, 2243.

(10) Maeda, K.; Takata, T.; Hara, M.; Saito, N.; Inoue, Y.; Kobayashi, H.; Domen, K. J. Am. Chem. Soc. 2005, 127, 8286.

(11)(a) Kanan, M. W.; Nocera, D. G. Science 2008, 321, 1072. (b) Kim, T. W.; Choi, K. S. Science 2014, 343, 990.

(12) Zhai, Q.; Xie, S.; Fan, W.; Zhang, Q.; Wang, Y.; Deng, W.; Wang, Y. Angew. Chem. Int. Ed. 2013, 52, 5776.

(13) Bonin, J.; Robert, M.; Routier, M. J. Am. Chem. Soc. 2014, 136, 16768.

(14) Gust, D.; Moore, T. A.; Moore, A. L. Acc. Chem. Res. 2oo9, 42, 1890.

(15) Cook, T. R.; Dogutan, D. K.; Reece, S. Y.; Surendranath, Y.; Teets, T. S.; Nocera, D. G. Chem. Rev. 2010, 11o, 6474.

(16) Schlapbach, L.; Züttel, A. Nature 2oo1, 414, 353.

(17) Yang, J.; Sudik, A.; Wolverton, C.; Siegel, D. J. Chem. Soc. Rev. 2o10, 39, 656.

(18) Eberle, U.; Felderhoff, M.; Schüth, F. Angew. Chem. Int. Ed. 2oo9, 48, 6608.

(19) Rosi, N. L.; Eckert, J.; Eddaoudi, M.; Vodak, D. T.; Kim, J.; O’Keeffe, M.; Yaghi, O. M. Science $\mathbf{2 0 0 3}, 300,1127$.

(20) Orimo, S.; Nakamori, Y.; Eliseo, J. R.; Züttel, A.; Jensen, C. M. Chem. Rev. 2oo7, 107, 4111.

(21) Hamilton, C. W.; Baker, R. T.; Staubitzc, A.; Manners, I. Chem. Soc. Rev. 2oo9, $38,279$.

(22) For a recent patent: Pez, G. P.; Scott, A. R.; Cooper, A. C.; Cheng, H.; Wilhelm, F. C.; Abdourazak, A. H. U.S. Patent 7351395 and 7429372, 2008, and references cited therein.

(23) Bratlie, K. M.; Lee, H.; Komvopoulos, K.; Yang, P.; Somorjai, G. A. Nano Lett. $\mathbf{2 0 0 7 , ~ 7 , ~} 3097$.

(24) Riad, M.; Mikhail, S. Catal. Comm. 2oo8, 9, 1398.

(25) Li, L.; Li, G. D.; Yan, C.; Mu, X. Y.; Pan, X. L.; Zou, X. X.; Wang, K. X.; Chen, J. S. Angew. Chem. Int. Ed. 2011, 50, 8299.

(26) Li, L.; Cai, Y. Y.; Li, G. D.; Mu, X. Y.; Wang, K. X.; Chen, J. S. Angew. Chem. Int. Ed. 2012, 51, 4702.

(27) Li, L.; Fan, S.; Mu, X.; Mi, Z.; Li, C. J. J. Am. Chem. Soc. 2014, 136, 7793.

(28) Zhang, J.; Zhang, M.; Jin, Z.; Wang, J.; Zhang, Z. Appl. Surf. Sci. 2o12, 258, 3991.

(29) Tauster, S. J.; Fung, S. C.; Garten, R. L. J. Am. Chem. Soc. 1978, 10o, 170. 
(30) (a) Rui, Z.; Chen, L.; Chen, H.; Ji, H. Ind. Eng. Chem. Res. 2014, 53, 15879. (b) Ioannides, T.; Verykios, X. E. J. Catal. 1996, 161, 560.

(31) (a) Alexeev, O. S.; Chin, S. Y.; Engelhard, M. H.; Ortiz-Soto, L.; Amiridis, M. D. J. Phys. Chem. B 2005, 109, 23430. (b) Schäfer, S.; Wyrzgol, S. A.; Caterino, R.; Jentys, A.; Schoell, S. J.; Hävecker, M.; Gericke, A. K.; Lercher, J. A.; Sharp, I. D.; Stutzmann, M. J. Am. Chem. Soc. 2012, 134, 12528.

(32) Shiraishi, Y.; Sakamoto, H.; Fujiwara, K.; Ichikawa, S.; Hirai, T. ACS Catal. 2014, 4, 2418.

(33) Kale, M. J.; Avanesian, T.; Xin, H.; Yan, J.; Christopher, P. Nano Lett. 2014, 14, 5405 .

(34） Wiest, O.; Houk, K. N.; Black, K. A.; Thomas IV, B. J. Am. Chem. Soc. 1995, 117, 8594 . 